\title{
Glucose restriction induces cell death in parental but not in homeodomain-interacting protein kinase 2-depleted RKO colon cancer cells: molecular mechanisms and implications for tumor therapy
}

\author{
A Garufi ${ }^{1}$, A Ricci ${ }^{2}$, D Trisciuoglio ${ }^{3}$, E lorio ${ }^{2}$, G Carpinelli ${ }^{2}$, G Pistritto ${ }^{4}, M$ Cirone ${ }^{5}$ and G D'Orazi ${ }^{\star * 1,6}$
}

Tumor cell tolerance to nutrient deprivation can be an important factor for tumor progression, and may depend on deregulation of both oncogenes and oncosuppressor proteins. Homeodomain-interacting protein kinase 2 (HIPK2) is an oncosuppressor that, following its activation by several cellular stress, induces cancer cell death via p53-dependent or -independent pathways. Here, we used genetically matched human RKO colon cancer cells harboring wt-HIPK2 (HIPK2 ${ }^{+l+}$ ) or stable HIPK2 siRNA interference (siHIPK2) to investigate in vitro whether HIPK2 influenced cell death in glucose restriction. We found that glucose starvation induced cell death, mainly due to c-Jun NH2-terminal kinase activation, in HIPK2 ${ }^{+l+}$ cells compared with siHIPK2 cells that did not die. ${ }^{1} \mathrm{H}$-nuclear magnetic resonance quantitative metabolic analyses showed a marked glycolytic activation in siHIPK2 cells. However, treatment with glycolysis inhibitor 2-deoxy-D-glucose induced cell death only in HIPK2 ${ }^{+1+}$ cells but not in siHIPK2 cells. Similarly, siGlut-1 interference did not re-establish siHIPK2 cell death under glucose restriction, whereas marked cell death was reached only after zinc supplementation, a condition known to reactivate misfolded p53 and inhibit the pseudohypoxic phenotype in this setting. Further siHIPK2 cell death was reached with zinc in combination with autophagy inhibitor. We propose that the metabolic changes acquired by cells after HIPK2 silencing may contribute to induce resistance to cell death in glucose restriction condition, and therefore be directly relevant for tumor progression. Moreover, elimination of such a tolerance might serve as a new strategy for cancer therapy.

Cell Death and Disease (2013) 4, e639; doi:10.1038/cddis.2013.163; published online 23 May 2013

Subject Category: Cancer Metabolism

Tumor cell proliferation and survival are basically maintained by oxygen and nutrients, especially glucose, supplied by the blood. For this reason, angiogenesis is considered closely involved in tumorigenesis. ${ }^{1}$ Some tumor cells acquire tolerance to glucose starvation (glu stv), which may depend on hypoxia condition. ${ }^{2-4}$ Hypoxia-inducible factor 1 (HIF-1) is a heterodimeric transcription factor with constitutive HIF-1 $\beta$ subunit and the HIF-1 $\alpha$ subunit stabilized by low intracellular oxygen or genetic alteration. HIF-1 target genes that regulate glucose metabolism include the glucose transporter-1 (Glut-1), as well as multiple enzymes required for glycolysis. ${ }^{5}$ Homeodomain-interacting protein kinase 2 (HIPK2) is a corepressor protein that regulates the transcription of numerous proteins involved in tumor progression and development. ${ }^{6}$ We previously reported that HIPK2 represses HIF- $1 \alpha$ transcription; thus, HIPK2 depletion induces a pseudohypoxic phenotype with $\mathrm{HIF}-1 \alpha$ upregulation and angiogenesis that results in increased tumor growth in vivo and in chemoresistance. ${ }^{7-9}$ This finding parallels the overexpression of HIF- $1 \alpha$ in many human cancers, including colon, brain, breast, and so on, which is associated with poor prognosis and failure of tumor treatment. ${ }^{5}$ Hypoxia and HIF- $1 \alpha$ have been found to downregulate HIPK2 in a negative regulatory loop, ${ }^{10,11}$ whereas zinc treatment has been shown to downregulate HIF-1 $\alpha$ with restoration of HIPK2 activity. ${ }^{12-14}$

HIPK2 induces cell death by activating p53-dependent and independent pathways. ${ }^{9,15}$ HIPK2 activation by DNA damage (for example, ionizing radiation, IR, UV light) or antitumor drugs (for example, cisplatin, adryamicin, roscovitin) phosphorylates p53 at Ser46 with induction of p53 apoptotic function. ${ }^{15-18}$ HIPK2 participates in the c-Jun $\mathrm{NH} 2$-terminal kinase (JNK) activation and apoptosis in p53 null cells. ${ }^{19}$ Chronic HIPK2 depletion impairs p53 function by inducing p53 protein misfolding that can be reversed by zinc supplementation. ${ }^{20,21}$ P53 is a zinc-binding transcription factor that needs proper folding for DNA binding and transactivating functions

\footnotetext{
${ }^{1}$ Molecular Oncogenesis Laboratory, Department of Experimental Oncology, Regina Elena National Cancer Institute, Rome, Italy; ${ }^{2}$ Cell Biology and Neurosciences Department, Istituto Superiore di Sanità (ISS), Rome, Italy; ${ }^{3}$ Experimental Chemotherapy Laboratory, Regina Elena National Cancer Institute, Rome, Italy; ${ }^{4}$ Section of Pharmacology, Department of Neuroscience, University "Tor Vergata", Rome, Italy; ${ }^{5}$ Department of Experimental Medicine, Istituto Pasteur-Fondazione Cenci Bolognetti, Sapienza University, Rome, Italy and 'Department of Medical, Oral and Biotechnological Sciences, University "G. d'Annunzio", Chieti, Italy

${ }^{*}$ Corresponding author: G D'Orazi, Department of Medical, Oral and Biotechnological Sciences, University "G. d'Annunzio", Via de Vestini, 31, Chieti 66013, Italy. Tel: +39 065266 2529; Fax: +39 06418 0526; E-mail: gdorazi@unich.it

Keywords: HIPK2; glucose; tumor; cell death; autophagy; zinc supplementation

Abbreviations: ${ }^{1} \mathrm{H}-\mathrm{NMR},{ }^{1} \mathrm{H}$-nuclear magnetic resonance; 2-DG, 2-deoxy-D-glucose; CQ, cloroquine; HIF-1, hypoxia-inducible factor 1; HIPK2, Homeodomaininteracting protein kinase 2; JNK, c-Jun NH2-terminal kinase; LC3, microtubule-associated protein light chain 3

Received 24.1.13; revised 28.3.13; accepted 08.4.13; Edited by C Munoz-Pinedo
} 
for oncosuppressor activity; ${ }^{22}$ it also has important roles in the regulation of cellular metabolism in cancer cells. ${ }^{23}$ Loss of p53 enhances aerobic glycolysis, resulting in the development of more aggressive tumors, ${ }^{24}$ and enhances oxidative pentose phosphate pathway (PPP) flux through p53 protein binding to glucose-6-phosphate dehydrogenase (G6PD), the first and rate-limiting enzyme of the PPP that has an important role in biosynthesis. ${ }^{25}$ Interestingly, the inhibition of G6PD by p53 is independent of transcription and is a cytoplasmic, not nuclear, function of $\mathrm{p53}$, probably attributed to the native conformation of $p 53 .{ }^{25}$

Autophagy is a degradative process through which damaged organelles and misfolded proteins are targeted for disruption via the lysosomes. In cancer, autophagy may contribute to tumor cell survival. As cancer cells experience higher metabolic demands than normal cells, due to their altered glycolytic metabolism, they may depend more heavily on autophagy for survival. Therefore, inhibition of autophagy may enhance the therapeutic benefits of various cancer therapies. ${ }^{26}$

In the current study, we investigated the effect of HIPK2 depletion in cancer cell response to glucose restriction. HIPK2 silencing impaired RKO colon cancer cell death under limiting glucose availability or under inhibition of glucose metabolism by 2-deoxy-D-glucose (2-DG), compared with HIPK2-proficient cells that instead underwent marked cell death. Zinc supplementation reduced HIPK2 siRNA interference (siHIPK2) cell resistance to glucose deprivation inducing cell death. Moreover, blocking the glu stv-induced autophagy increased HIPK2 ${ }^{+/+}$cell death and re-established siHIPK2 cell death. These findings could be directly relevant to the documented role of HIPK2 as a tumor suppressor, because absence of HIPK2 might confer to tumor cells the metabolic adaptability necessary to survive longer in adverse environment.

\section{Results}

${ }^{1} \mathrm{H}-\mathrm{NMR}$ analyses detected different metabolic profiles in HIPK2-proficient compared with HIPK2-depleted cancer cells. To evaluate the effect of HIPK2 depletion on cellular bioenergetics, we compared metabolic measurements of human colorectal carcinoma-derived RKO cells that retain HIPK2 $\left(\mathrm{HIPK}^{+/+}\right.$) with their isogenic derivatives in which the HIPK2 gene had be stably knocked down by siRNA interference (siHIPK2, with HIPK2 mRNA reduction of about $70 \%){ }^{27}$ The siHIPK2 cell line constitutes a bona fide model of tumor progression. ${ }^{7,8}$ Seven independent (biological) replicates of HIPK2 ${ }^{+/+}$and SiHIPK2 cells were grown under the same optimal conditions. One-dimensional ${ }^{1} \mathrm{H}$-nuclear magnetic resonance $\left({ }^{1} \mathrm{H}-\mathrm{NMR}\right)$ spectra of metabolic extracts were measured and used in the qualitative and quantitative analysis. Representative one-dimensional ${ }^{1} \mathrm{H}$-NMR spectra of aqueous extracts is shown in Figure 1a with peak assignments. The qualitative analysis of the major variances in the spectra was performed directly by using principal component analysis (PCA), an unsupervised method allowing orthogonal decomposition of variance associated with the analyzed metabolites. ${ }^{28}$ As shown in Figure $1 \mathrm{~b}$, score plot of the first two principal components, PC1 and
PC2, of intracellular metabolites, revealed a clear difference between the two cell lines with a confidence level of $80 \%$. In particular, phosphocholine (PCho, 3.22 p.p.m.), myo-inositol (myo-ino 4.05 p.p.m.), lactate (Lac, 1.33 p.p.m.), and total creatine (tCr 3.04 p.p.m.) were responsible for segregation in two separate cluster in PC1 and PC2 score plot, as shown in 2D loading plot (Figure 1c). Quantitative NMR analyses showed intracellular higher levels in siHIPK2 with respect to $\mathrm{HIPK}^{+/+}$cells of relevant metabolites involved in glycolysis, tricarboxylic acid (TCA) cycle, and phosphatidylcholine metabolism (Figure 1d). In particular, siHIPK2 cells showed significant increase of choline-containing metabolites (tCho, $P=0.002$ ), glycine (gly; $P=0.006$ ), and intracellular Lac $(P=0.015)$ and alanine (Ala; $P=0.007)$, compared with HIPK2 $^{+/+}$cells (Figure 1d). These altered metabolic profiles might be potential novel indicators of tumor progression, as reported. ${ }^{29}$ Moreover, glutamate $(P=0.004)$ and glutamine $(P=0.007)$ involved in TCA cycle increased in siHIPK2 cells, while significant decrease $(P=0.007)$ in creatine plus phosphocreatine (tCr) levels were observed in siHIPK2 compared with $\mathrm{HIPK}^{+/+}$cells (Figure 1d). Altogether, these data show that chronic HIPK2 depletion strongly affected metabolic profiles of RKO cells, and in particular, the significant increase in Lac, Ala, and gly suggested a marked glycolytic activation.

Silencing of HIPK2 protects tumor cells from glu stvinduced cell death. Glycolytic metabolism promotes proliferation of cancer cells, but it also protects them from cell death induced by growth factor withdrawal or nutrient starvation; ${ }^{30}$ therefore, we challenged $\mathrm{HIPK}^{+/+}$and siHIPK2 cells with glucose restriction. Cells were grown with normal glucose concentration $(25 \mathrm{mM}$, mock) or in media lacking glucose (glu stv). Cell viability showed time-dependent increase of cell death in HIPK2 ${ }^{+/+}$cells, whereas HIPK2 knockdown significantly protected tumor cells from glu stv-induced cell death $(P<0.01$; Figure 2a, left panels); as also evidenced macroscopically (Figure $2 \mathrm{~b}$, upper panel) and microscopically (Figure 2b, lower panel), where evident signs of cell death were present in HIPK2 ${ }^{+1+}$ cells after $24 \mathrm{~h}$ starvation (1d stv), while siHIPK2 cells appeared still alive after $48 \mathrm{~h}$ starvation (2d stv). Cell proliferation analysis showed reduced cell growth of glucose-starved HIPK2 ${ }^{+1+}$ cells, in agreement with the cell death induction (Figure 2a, upper/right panel); on the other hand, although siHIPK2 cells did not die in glucose-free condition, they underwent growth arrest (Figure 2a, lower/right panel). Cell death was obtained in HIPK2 ${ }^{+1+}$ compared with siHIPK2 cells also with reduced glucose concentration $(2.5 \mathrm{mM}, 1: 10)$. Extension of the glu stv to 2 days further confirmed the HIPK2 requirement for starvation-induced cell death: substantial numbers of alive cells were observed in the siHIPK2 cells whereas in the HIPK2 $^{+/+}$ones they appeared mostly dead (Figure $2 b$ ), suggesting a greater ability of siHIPK2 cells to deal with glucose deprivation. Thus, HIPK2 depletion induced marked lactate production under normal culture condition that did not change during glu stv, compared with HIPK2 ${ }^{+/+}$cells where glu stv significantly decreased lactate production (Figure 2c).

Next, we performed Annexin V/propidium iodide (PI) staining that allows the discrimination of viable cells (Annexin 
a

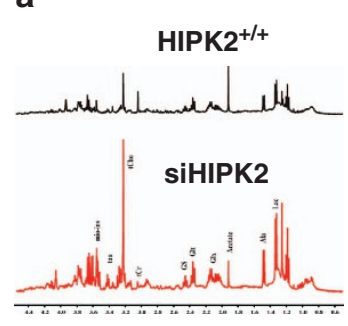

ppm b

PC2

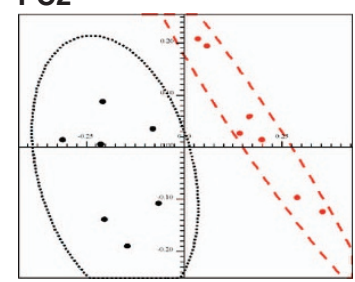

PC1
C

PC2

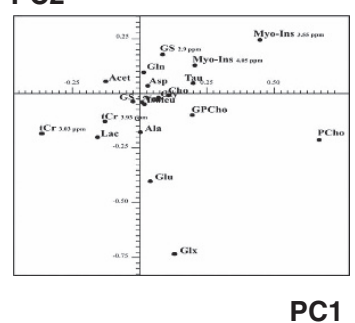

d

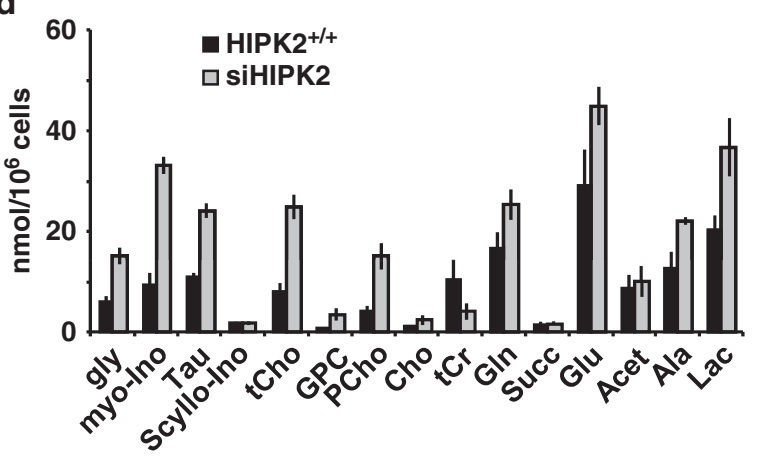

Figure $1{ }^{1} \mathrm{H}$-NMR analyses of different metabolic profiles in HIPK2-proficient (HIPK2 ${ }^{+/+}$) compared with HIPK2-depleted (siHIPK2) cancer cells. (a) Representative ${ }^{1} \mathrm{H}-\mathrm{NMR}$ spectra $(400 \mathrm{MHz})$ of aqueous extract from HIPK2 ${ }^{+1+}$ and siHIPK2 cancer cells. Peak assignments: myo-ino; tau (taurine); tCho (total choline-containing metabolites) resonance including choline (Cho), phosphocholine (PCho); glycerophosphocholine (GPCho); tCr (total creatine: creatine plus phosphocreatine); GS (glutathione); Glt (glutamate); Glx (glutamate + glutamine + glutathione); Acetate; alanine (Ala); and lactate (Lac). p.p.m., parts per million. (b) Score plot of the first two principal components (PC1 and PC2) in HIPK2 ${ }^{+1+}$ (dotted circle) and siHIPK2 (dashed circle) cells. Level of confident $=80 \%$. (c) $2 \mathrm{D}$ loading plot showing the critical metabolites for different segregation between the two cell lines. In particular, PCho, 3.22 p.p.m.; myo-ino, 4.05 p.p.m.; Lac, 1.33 p.p.m.; and tCr, 3.04 p.p.m. were responsible for segregation in two separate cluster in PC1 versus PC2 score plot. (d) Intracellular concentrations (nmol/10 ${ }^{6}$ cells) of ${ }^{1} \mathrm{H}-\mathrm{NMR}$ detectable metabolites in HIPK2 ${ }^{+1+}$ and siHIPK2 cells. Significant increases in: Lac, $P=0.015$; Ala, $P=0.007$; glycine (gly, $P=0.006$; tCho, $P=0.002$; Glt, $P=0.004$; and glutamine, $P=0.007$. Significant decrease intCr levels in siHIPK2 compared with HIPK2 ${ }^{+1+}$ cells $(P=0.007)$

$\mathrm{V}^{-} / \mathrm{PI}^{-}$), early apoptotic (Annexin $\mathrm{V}^{+} / \mathrm{PI}^{-}$), and late apoptotic or necrotic cells (Annexin $\mathrm{V}^{+} / \mathrm{PI}^{+}$). As shown in Figures $2 \mathrm{~d}$ and $\mathrm{e}, 24 \mathrm{~h}$ glu stv increased the percentage of both early (about $7 \%$ compared with mock) and late apoptotic or necrotic events (about 36\% compared with mock) in HIPK2 ${ }^{+/+}$cells, whereas it did not induce apoptosis or necrotic cell death in siHIPK2 cells. In agreement, PARP cleavage was observed only in HIPK2 ${ }^{+/+}$cells $24 \mathrm{~h}$ after glu stv, compared with siHIPK2 cells (Figure 2f). Of note, replenishment with full medium, which might mimic angiogenesis in vivo or increased dietary glucose intake, led to a timedependent increase of siHIPK2 but also of $\mathrm{HIPK}^{+/+}$cell number, with a slow reduction of HIPK2 ${ }^{+/+}$cell death (Supplementary Figure S1). These latter data suggest that siHIPK2 cells and also the few remaining HIPK2 $2^{+1+}$ ones were still viable after, respectively, 48 and $24 \mathrm{~h}$ glu stv and capable of resuming cell proliferation as soon as nutrient supply was provided. Altogether, these results demonstrate that HIPK2 silencing protected RKO colon cancer cells from glu stv-induced cell death.

JNK activity is engaged in death induced by glucose deprivation. To underline the role of HIPK2 in glu stvinduced cell death, we attempted to analyze pathways known to be modified by HIPK2. Glucose deprivation has been shown to phosphorylate p53 at Ser46, which is a target of
HIPK2 kinase activity, ${ }^{16,17}$ for apoptotic cell death. ${ }^{31}$ We found that Ser46 was slightly phosphorylated in HIPK2 ${ }^{+1+}$ cells after $24 \mathrm{~h}$ glucose restriction and absent in siHIPK2 cells (Supplementary Figure S2), indicative of a late involvement of HIPK2/p53Ser46 in cell death in this setting. HIPK2 has been shown to induce JNK phosphorylation to trigger apoptosis. ${ }^{19}$ Thus, JNK phosphorylation in HIPK2 ${ }^{+/+}$after 16 and $24 \mathrm{~h}$ glu stv was markedly impaired in siHIPK2 cells (Figure 3a); JNK activity was monitored by C-Jun phosphorylation that was indeed absent in siHIPK2 cells although showed reduced c-Jun expression level (Figure 3a). The role of JNK in glu stv-induced cell death was evaluated by stable transfection of the JNK1-APF mutant (DN-JNK1) ${ }^{32}$ in RKOHIPK2 ${ }^{+1+}$ cells (Figure 3b). As shown in Figure 3c, overexpression of the inactivatable DN-JNK1 mutant in HIPK2 ${ }^{+1}$ + cells markedly abolished glu stv-induced c-Jun phosphorylation and impaired cell death (Figure $3 \mathrm{~d}$ ), as also evidenced microscopically (Figure $3 e$ ).

HIPK2 is an unstable protein that undergoes degradative ubiquitination in basal condition. ${ }^{9,15}$ After induction, HIPK2 is temporarily stabilized and its activity may be regulated by caspase-mediated removal of an autoinhibitory domain, resulting in its hyperactivation. ${ }^{33}$ Here, we found a slight induction of HIPK2 expression level in HIPK2 ${ }^{+/+}$cells after $8 \mathrm{~h}$ glu stv, which decreased in the subsequent time points, suggestive of HIPK2 activation, ${ }^{9,27,33}$ while siHIPK2 cells 
a
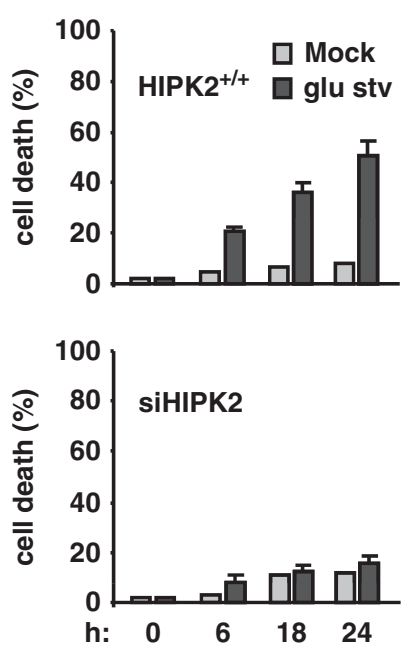
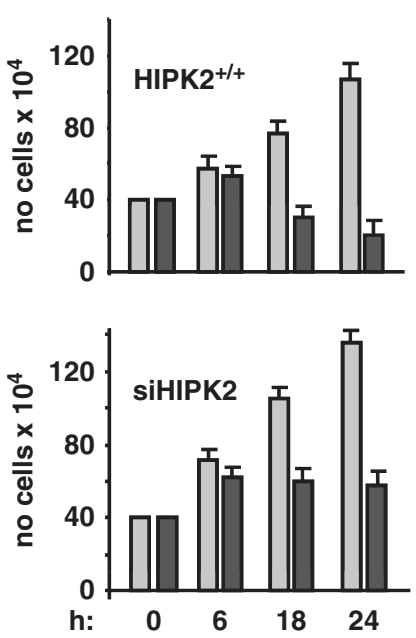

b
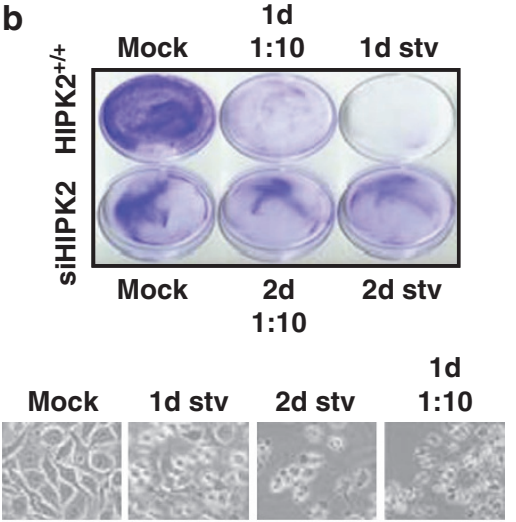

HIPK2 $^{+/+}$

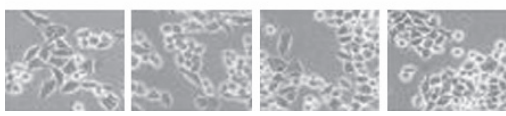

SiHIPK2

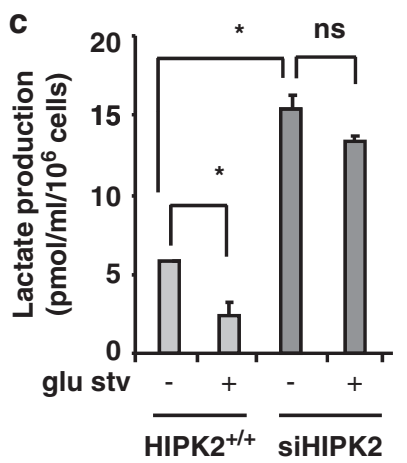

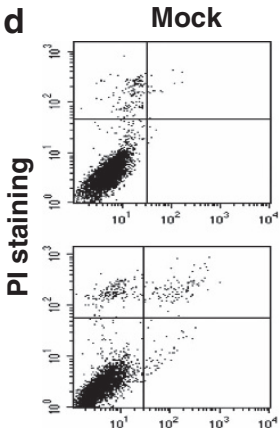

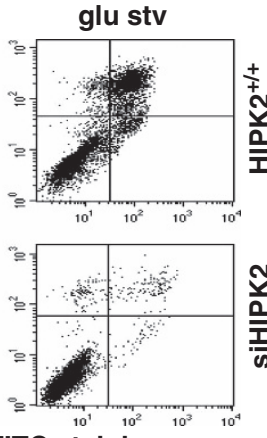

Annexin V-FITC staining

glu stv

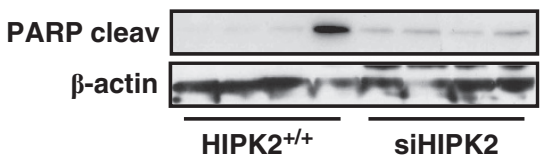

Figure 2 siHIPK2 cells show resistance to glu stv-induced cell death. (a) HIPK2 ${ }^{+1+}$ and siHIPK2 subconfluent cells were seeded and the day after washed with PBS before culturing in glucose-free medium (glu stv). Cell death (left panels) and proliferation (right panels) were analyzed by trypan blue staining after 6,18 , and $24 \mathrm{~h}$ treatment. The result is the mean of three independent experiments performed in triplicate \pm S.D. (b) HIPK2 ${ }^{+1+}$ and siHIPK2 cells were cultured in glucose-free or low glucose $(1: 10 \mathrm{stv})$ media for 1 or 2 days ( $1 \mathrm{~d}, 2 \mathrm{~d}$ stv) after which live cell images were taken (bottom panel), fixed. and stained with crystal violet (upper panel). A representative result of three experiments is shown. (c) Lactate production into medium of HIPK2 ${ }^{+1+}$ and siHIPK2 cultured for $16 \mathrm{~h}$ in glucose-free (glu stv) condition. Results are the mean of two independent experiments performed in quadruplicate, \pm S.D. ${ }^{*}$, the difference were significant at $P<0.05$. (d) Cytofluorimetric dot plot analysis of the Annexin V-FITC versus propidium iodide (PI) staining performed in HIPK2 ${ }^{+/+}$and siHIPK2 cells after $24 \mathrm{~h}$ of growth in complete medium (mock) or glucose-free medium (glu stv). A representative experiment out of three performed with similar results is shown. Annexin $\mathrm{V}^{+} / \mathrm{PI}^{-}$- and Annexin $\mathrm{V}^{+} / \mathrm{PI}^{+}$-stained cells were considered early apoptotic and late apoptotic or necrotic cells, respectively. (e) Percentage of Annexin $\mathrm{V}^{+} / \mathrm{PI}^{-}$- and Annexin $\mathrm{V}^{+} / \mathrm{PI}^{+}$-stained cells was calculated by cytofluorimetric analysis shown in (d) using CellQuest Software. (f) Equal amounts of total cell extracts from HIPK2 ${ }^{+1+}$ and siHIPK2 cells left untreated or treated with glucose-free medium (glu stv) for the indicated times were analyzed by western immunoblotting to assess PARP cleavage. Anti- $\beta$-actin was used as protein loading control

were negative (Supplementary Figure S2). In addition, chromatin immunoprecipitation (ChIP) showed that the binding of HIPK2 on HIF-1 $\alpha$ promoter, as previously shown, ${ }^{7}$ was strongly increased after $8 \mathrm{~h}$ of glu stv (Figure $3 \mathrm{f}$ ). Altogether, these results demonstrate that JNK activation is one of the signaling pathway involved in triggering cell death in glucosestarving RKO-HIPK2 ${ }^{+/+}$cells that was abrogated by HIPK2 depletion.
Targeting glycolysis by 2-DG or siGlut-1 does not induce siHIPK2 cell death under glu stv. Targeting aerobic glycolysis is a very promising approach as anticancer treatment. Among the glycolysis inhibitor in preclinical and clinical development is the inactive analog of glucose and hexokinase inhibitor, 2-DG. ${ }^{34,35}$ Therefore, we addressed the question of whether inhibition of glycolysis could re-establish glucose-starving siHIPK2 cell death. Treatment with 2-DG 
a

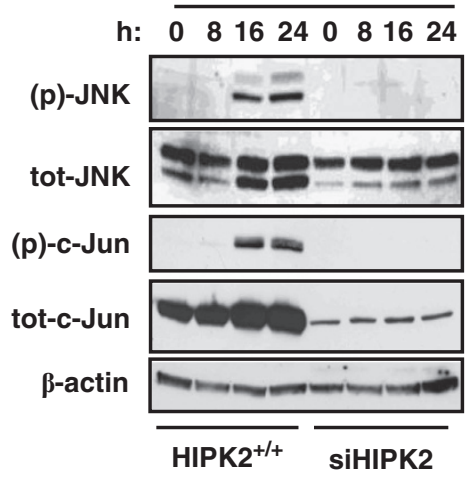

b

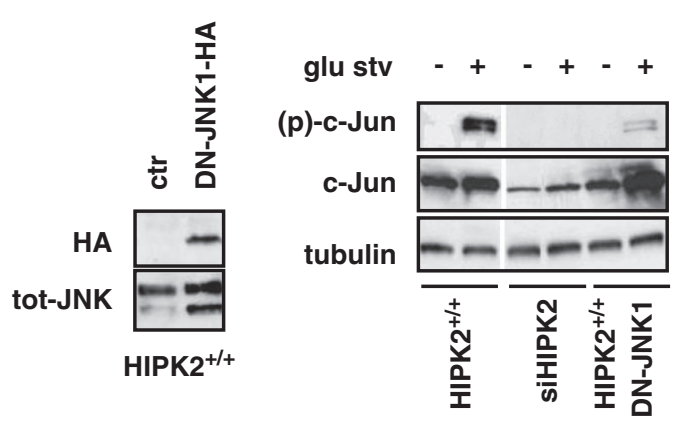

d

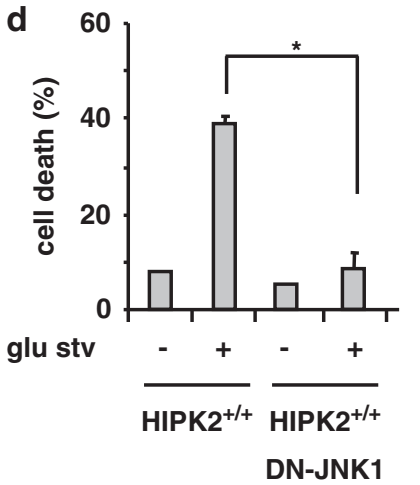

e Mock

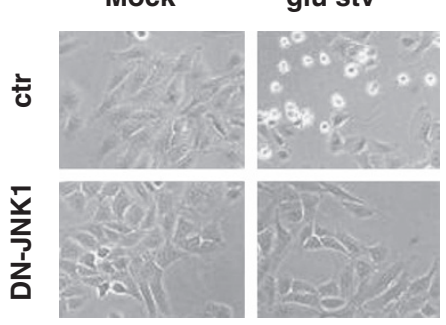

HIPK2 $^{+/+}$

Figure 3 JNK activity is involved in cell death induced by glucose deprivation. (a) Equal amount of total cell extracts from HIPK2 ${ }^{+/+}$and siHIPK2 cells cultured in glucose-free medium (glu stv) for the indicated times was analyzed by western immunoblotting with the indicated antibodies. Anti- $\beta$-actin was used as protein loading control. (b) RKO-HIPK2 ${ }^{+1+}$ cells were stably transfected with JNK1-APF-HA mutant (dominant negative, DN-JNK1) or with control vector ( - ). DN-JNK was detected by western immunoblotting with anti-HA antibody; total JNK is shown. (c) HIPK2 ${ }^{+1+}$ control, DN-JNK1-overexpressed cells, and siHIPK2 cells were cultured in glucose-free medium for $24 \mathrm{~h}$ before assaying for western immunoblotting with anti-(p)-c-Jun and tot-c-Jun. Anti-tubulin was used as protein loading control (d) HIPK2 ${ }^{+/+}$control and DN-JNK1overexpressed cells were cultured as in (c) and cell death was analyzed by trypan blue staining. The result is the mean of three independent experiments performed in triplicate \pm S.D. ${ }^{*} P=0.001$ (e) HIPK2 ${ }^{+1+}$ control and DN-JNK1-overexpressed cells were cultured as in (c) before live cell images were taken. A representative result out of three is shown. (f) ChIP analysis performed with anti-HIPK2 antibody on H1299 cells untreated or treated with glucose-free medium (8h) PCR analyses were performed on the immunoprecipitated DNA samples using specific primers for HIF-1 $\alpha$ promoter. A sample representing linear amplification of the total input chromatin (Input) was included as control. Additional controls included immunoprecipitation performed with nonspecific immunoglobulins (IgG)

ranging between 4 and $12 \mathrm{mM}$ for $48 \mathrm{~h}$ induced marked HIPK2 ${ }^{+1+}$ cell death, compared with siHIPK2 cells that did not die (Figure 4a), as also evidenced microscopically (Figure 4b). Replenishment of cell cultures with full medium increased cell number in both cell lines (Figures $4 \mathrm{~b}$ and $c+r e c)$, although it was more marked in siHIPK2 cells (Figure $4 \mathrm{c}+\mathrm{rec}$ ). Cell proliferation was also assessed by western immunoblotting of cyclin B1, which, in mammalian cells, has a critical role in the progression through mitosis. ${ }^{36}$ As shown in Figure 4c: lower panel, cyclin B1 almost completely disappeared after 2-DG treatment in both cell lines; however, replenishment of cell cultures with full medium $(+\mathrm{rec})$ efficiently restored cyclin B1 expression in both cell lines. These data indicate that HIPK2 ${ }^{+/+}$cells were more sensitive to cell death induced by glicolysis inhibition compared with siHIPK2 cells. However, both cell lines were capable of resuming cells' proliferation after glucose supply replenishment.

Next, we attempted to evaluate Glut-1 expression, as increased Glut-1 and likely of glycolytic flux enhances, rather than impairs, cell tolerance to low glucose availability. ${ }^{37} \mathrm{We}$ found Glut-1 upregulation in siHIPK2 cells compared with HIPK2 ${ }^{+/+}$cells both at mRNA and protein levels (Figure 4d), which was somehow expected, given that Glut-1 is both transcriptionally repressed by $\mathrm{p} 53^{38}$ and activated by HIF-1, being both molecules, respectively, inhibited and activated by HIPK2 depletion. ${ }^{7,20}$ Then, we inhibited Glut-1 expression by transient transfection with specific siRNA (Figure 3e: inset, about $60 \%$ Glut1 mRNA reduction compared with control). However, Glut-1 silencing was not sufficient to induce siHIPK2 cell death under glucose deprivation (Figure $4 \mathrm{e}$ ), suggesting that additional pathway other than Glut-1 upregulation might be involved in resistance to metabolic stressinduced cell death.

Zinc supplementation induces cell death in glucosestarved siHIPK2 cells. Next, we attempted to modify the siHIPK2 cell response to glucose deprivation by using zinc supplementation, which inhibits the HIF-1 activity and reverses p53 misfolding. ${ }^{13,20,21}$ Zinc treatment greatly 

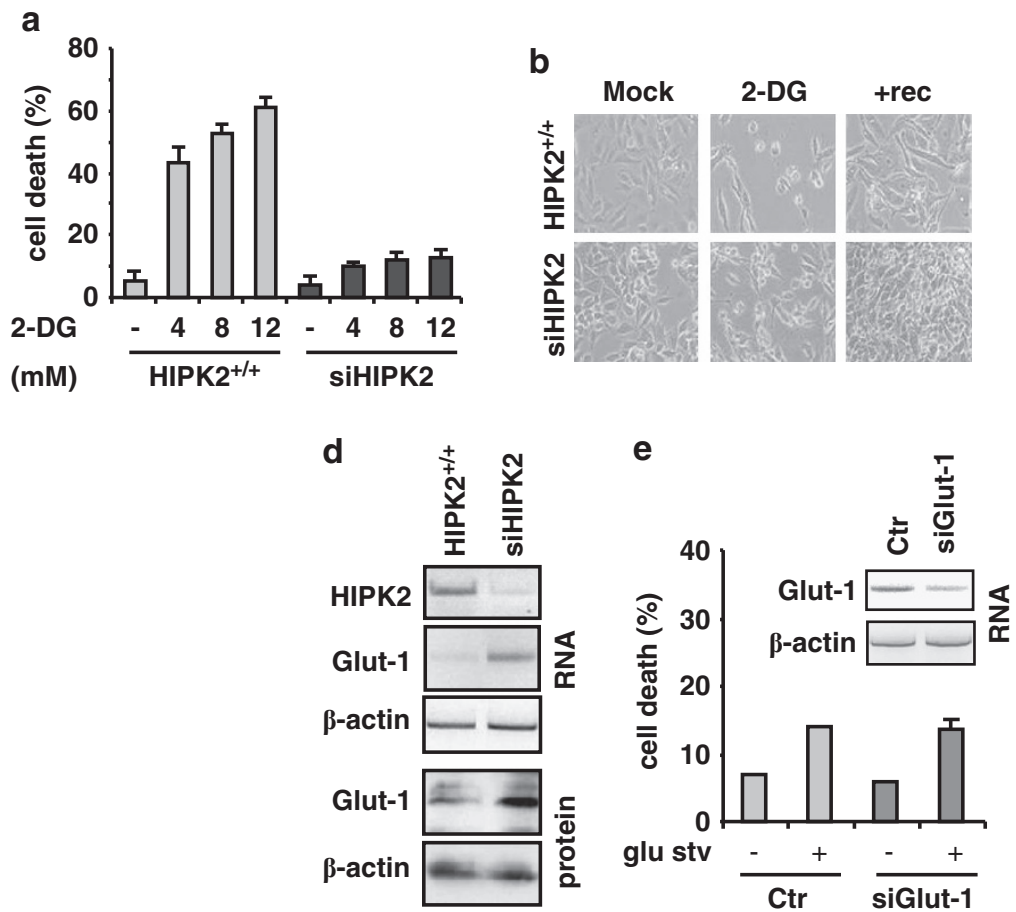

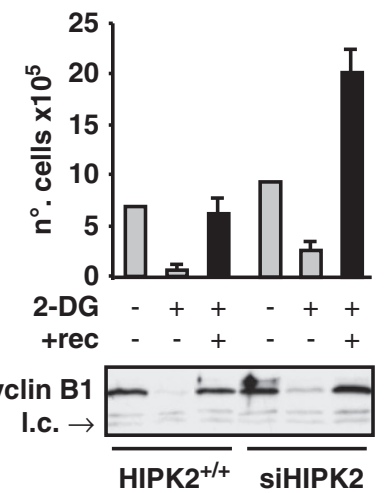

Figure 4 Targeting glycolysis by 2-DG or siGlut-1 does not re-establish glucose-starving siHIPK2 cell death. (a) HIPK2 $+1+$ and siHIPK2 subconfluent cells were seeded and the day after untreated $(-)$ or treated with 2-DG at 4,8 and $12 \mathrm{mM}$. Forty-eight hours later, trypan blue staining was performed. The result is the mean of three independent experiments performed in triplicate \pm S.D. (b) HIPK2 ${ }^{+/+}$and siHIPK2 were treated with $12 \mathrm{mM} 2-\mathrm{DG}$ for $48 \mathrm{~h}$, after which live cell images were taken, or fresh medium was replaced for $48 \mathrm{~h}\left(+\mathrm{rec}\right.$ ) before imaging. A representative result of three independent experiments is shown. (c) HIPK2 ${ }^{+} /+$and siHIPK2 subconfluent cells were seeded and the day after untreated $(-$ ) or treated with $12 \mathrm{mM}$ 2-DG for $48 \mathrm{~h}$ before fresh medium was replaced for $48 \mathrm{~h}$ ( + rec). Trypan blue staining was performed to assess live proliferating cells (upper panel). The result is the mean of three independent experiments performed in triplicate \pm S.D. Below is shown the western immunoblotting of cyclin B1. L.c, loading control. (d) HIPK2 ${ }^{+/+}$and siHIPK2 cells were assayed for RT-PCR analysis of HIPK2 and Glut-1 mRNA expression or Glut-1 protein levels. $\beta$-actin was used as loading control for both RT-PCR and western immunoblotting analyses. (e) siHIPK2 cells were transfected with siRNA for Glut-1 interference (Glut$1 \mathrm{mRNA}$ is shown in the inset) and $36 \mathrm{~h}$ after transfection cultured in glucose-free mediun (glu stv). Forty-eight hours after starvation, trypan blue staining was performed. The result is the mean of two independent experiments performed in duplicate \pm S.D

decreased the level of lactate production by glucose-starved siHIPK2 cells (Figure 5a) that correlated with significant increase of siHIPK2 cell death (Figure 5b). Similar siHIPK2 cell death was obtained with 2-DG in combination with zinc, whereas zinc treatment alone had almost no effect on cell viability (Figure 5b). Annexin V/PI staining confirmed that zinc supplementation in condition of glu stv induced about $55 \%$ of late apoptotic/necrotic cells (Annexin $\mathrm{V}^{+}, \mathrm{Pl}^{+}$) (Figures $5 c$ and d). Notably, no induction of early apoptosis (Annexin $\mathrm{V}^{+}, \mathrm{PI}^{-}$) was observed in the same experimental condition, and $<10 \%$ of cell death was evidenced by Annexin $\mathrm{V}$ staining in both glucose-starved or zinc-treated siHIPK2 cells (Figure $5 d$ ). These data suggest that zinc treatment could re-establish cell death response in glucosestarving siHIPK2 cells.

\footnotetext{
Autophagy contributes to cell resistance to nutrient deprivation. Autophagy contributes to the tolerance to nutrient deprivation in colorectal cancer cells. ${ }^{39}$ We evaluated the expression of microtubule-associated protein light chain 3 (LC3) protein that, after conversion from LC3-I to its autophagosome membrane-associated lipidated form LC3-II, is considered a cellular readout of autophagy. ${ }^{40}$ Figure $6 \mathrm{a}$ shows LC3 induction upon glu stv in both cell lines; treatment
}

with early inhibitor of autophagosome formation 3-methyladenine (3-MA $)^{40}$ did not dramatically reduce glu stv-induced LC3; on the contrary, treatment with inhibitor of autophagic protein degradation, cloroquine (CQ), ${ }^{40}$ strongly increased LC3-II expression under glu stv compared with CQ treatment alone, in both cell lines (Figure 6a), indicating the absence of defective autophagy. Autophagy is a key function of the lysosomal compartment ${ }^{41}$ and $C Q$ has been shown to disrupt lysosomal structure and function preventing effective autophagy degradation, leading to the accumulation of ineffective autophagosomes and cell death in cells reliant on autophagy for survival. ${ }^{42}$ We found that $C Q$ significantly increased cell death in glucose-starving siHIPK2 cells (Figure 6b) and slightly increased also glucose-starving $\mathrm{HIPK}^{+/+}$cell death, providing evidence that autophagy can contribute to tumor cell survival in this setting. Furthermore, Annexin V/PI staining showed that $\mathrm{CQ}$ increased the percentage of glucose-starving HIPK2 ${ }^{+/+}$late apoptotic/necrotic cell death that was not further increased by zinc supplementation (Figure 6c); on the other hand, the lack of cell death in glucose-starving siHIPK2 cells was reversed by adding $\mathrm{CQ}$ or zinc single treatments, and further increased by combining $\mathrm{CQ}$ and zinc supplementation (Figure 6c). These results suggest that autophagy is induced by glu stv, and that its 

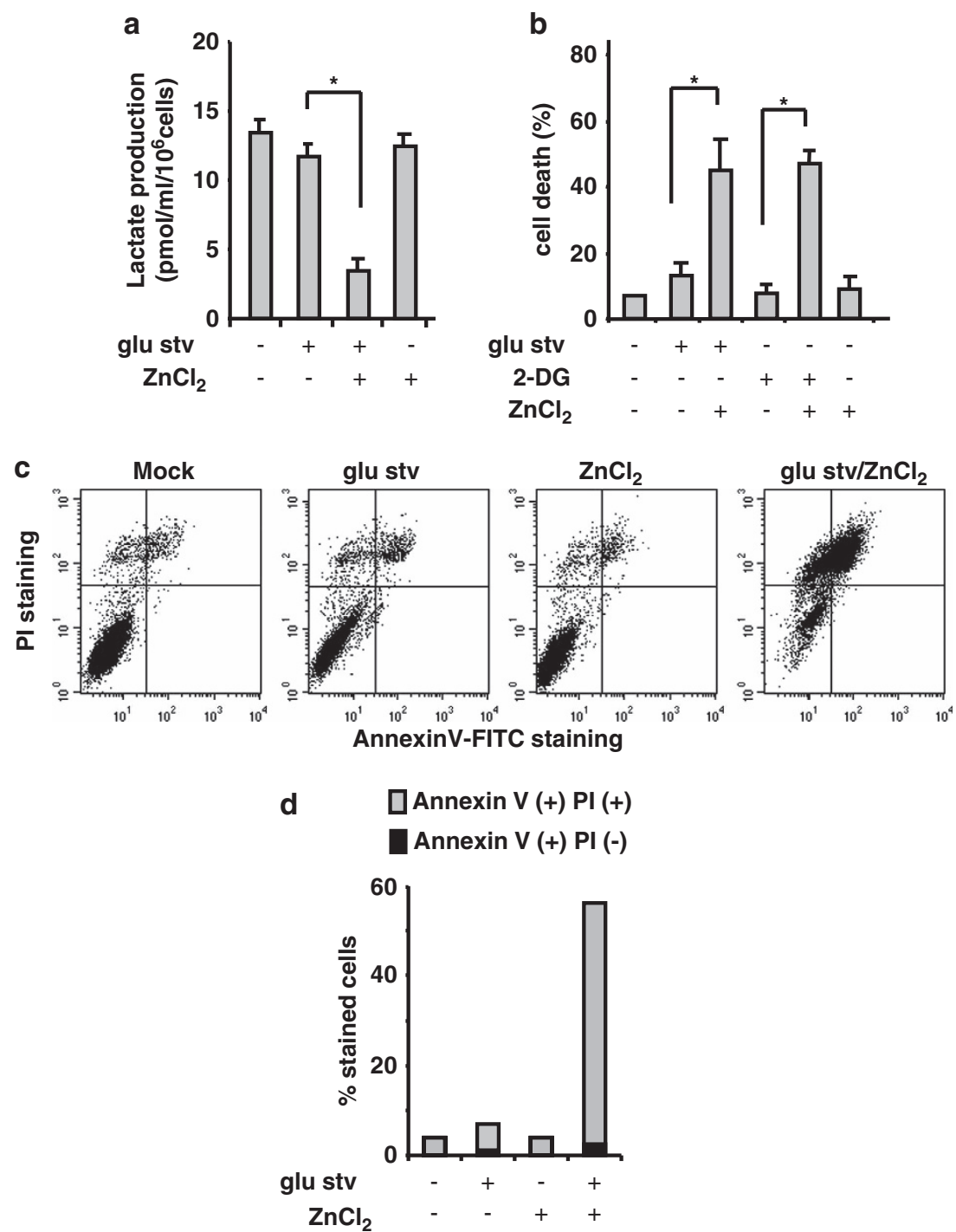

Figure 5 Zinc supplementation induces cell death in glucose-staning siHIPK2 cells. (a) Lactate production in medium of HIPK2 ${ }^{+/+}$cells cultured for $16 \mathrm{~h}$ in glucose-free medium (glu stv) alone or in combination with $\mathrm{ZnCl}_{2}(100 \mu \mathrm{M})$. Results are the mean of two independent experiments performed in quadruplicate, \pm S.D. *, the difference was significant at $P<0.05$. (b) siHIPK2 cells were cultured in glucose-free medium (glu stv) or treated with $12 \mathrm{mM} 2-\mathrm{DG}$ alone for $48 \mathrm{~h}$ or in combination with $\mathrm{ZnCl}_{2}(100 \mu \mathrm{M})$, before trypan blue staining was performed. The result is the mean of three independent experiments performed in duplicate \pm S.D. * $P<0.05$. (c) Cytofluorimetric dot plot analysis of the Annexin V-FITC versus propidium iodide $(\mathrm{Pl})$ staining of siHIPK2 cells cultured with glucose-free medium (glu stv) for $48 \mathrm{~h}$ alone or in combination with $\mathrm{ZnCl}_{2}(100 \mu \mathrm{M})$. A representative experiment out of three performed with similar results is shown. Annexin $\mathrm{V}^{+} / \mathrm{PI}^{-}$and Annexin $\mathrm{V}^{+} / \mathrm{PI}^{+}$were considered early apoptotic and late apoptotic or necrotic cells, respectively. (d) Percentage of Annexin $\mathrm{V}^{+} / \mathrm{PI}^{-}$and Annexin $\mathrm{V}^{+} / \mathrm{PI}^{+}$cells was calculated by cytofluorimetric analysis shown in (c) using CellQuest Software

inhibition slightly increased cell death in sensitive $\mathrm{RKO}^{+/+}$ while re-established cell death after glu stv particularly in resistant siHIPK2 cells that could be further improved by zinc supplementation.

We finally analyzed JNK phosphorylation and found that autophagy inhibition did not reverse JNK inhibition in siHIPK2 cells (Figure 7a), suggesting the modulation of additional pathways leading to cell death. In previous studies, we found that HIPK2 depletion induces constitutive Akt phosphorylation, ${ }^{43}$ which contributes to cell death resistance. Akt regulates many biological processes, such as proliferation, apoptosis and growth, and is involved in tumor progression. ${ }^{44}$ Here, we found that Akt phosphorylation was markedly inhibited by $C Q$ treatment in glucose-starving siHIPK2 cells
(Figure 7b). Interestingly, also zinc supplementation reduced (p)-Akt in glucose-starving siHIPK2 cells (Figure 7b). These results indicate that autophagy is activated by glu stv in this setting and that autophagy inhibition abrogated signaling pathway of apoptosis resistance such as Akt that correlated with increased cell death.

\section{Discussion}

In this study we show that HIPK2 depletion changed RKO cancer cell response to glucose restriction; thus, whereas HIPK2 ${ }^{+1+}$ cells underwent death HIPK2-depleted cells did not. What was the mechanism of such resistance to metabolic stress? Solid tumors are dependent on glucose, but are 

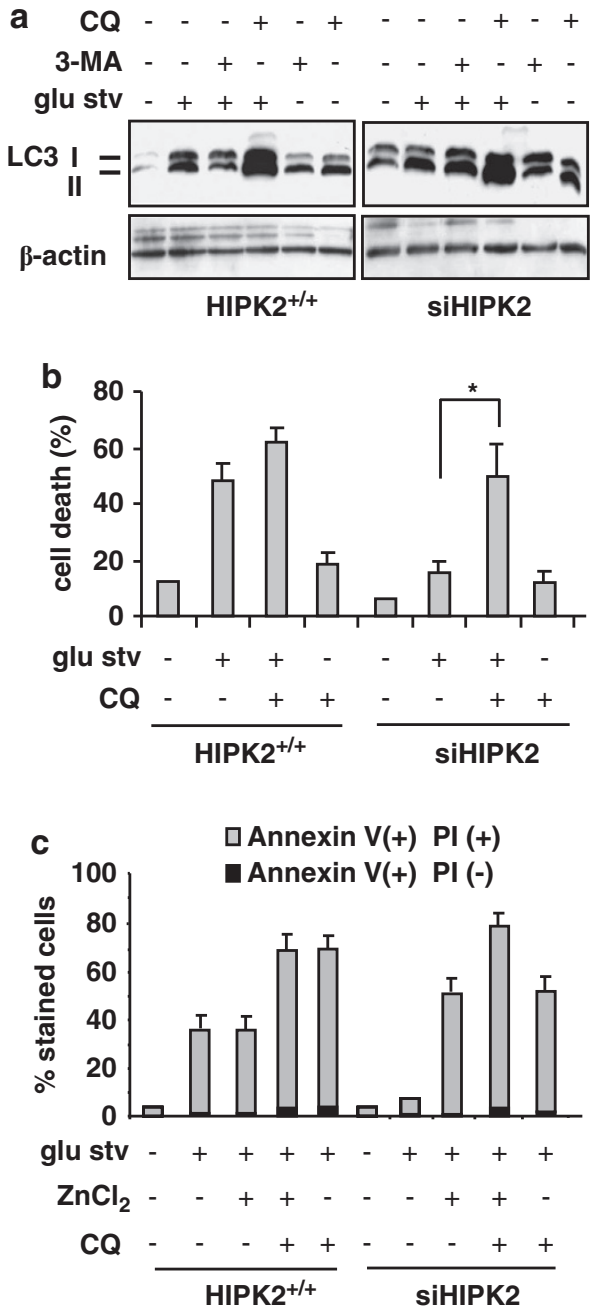

Figure 6 Inhibition of autophagy increased cell death. (a) Equal amount of total cell extracts from HIPK2 ${ }^{+I+}$ and siHIPK2 cells left untreated or treated for $24 \mathrm{~h}$ with glucose-free medium (glu stv) alone or in combination with autophagy inhibitors 3-MA $(5 \mathrm{mM})$ or $\mathrm{CQ}(25 \mu \mathrm{M})$ were assayed by western immunoblotting of LC3-1/II protein level. $\beta$-actin was used as protein loading control. A representative result of three independent experiments is shown. (b) HIPK2 ${ }^{+1+}$ and siHIPK2 cells were cultured for $24 \mathrm{~h}$ in glucose-free (glu stv) medium alone or in combination with $\mathrm{CQ}$ $(25 \mu \mathrm{M})$, before trypan blue staining was performed. The result is the mean of three independent experiments performed in duplicate \pm S.D. ${ }^{*} P=0.001$. (c) siHIPK2 cells were cultured in glucose-free medium (glu stv) alone for $48 \mathrm{~h}$ or in combination with $\mathrm{ZnCl}_{2}(100 \mu \mathrm{M})$ and $\mathrm{CQ}(25 \mu \mathrm{M})$ before cell death analysis was performed by Annexin V/PI staining and evaluated by immunocytochemistry. Two hundred cells were counted in duplicate in two independent experiments and plotted as percentage compared with control, \pm S.D

generally glucose-deprived owing to poor vascularization. Therefore, cancer cells undergo metabolic reprogramming to better cope with nutrient deprivation. ${ }^{4,45} \mathrm{~A}$ distinct trait of the cancer metabolism is the unscheduled activation of glycolytic enzymes in normoxic conditions, indicated by increased cellular glucose uptake, hyperglycolysis, and lactate production. ${ }^{46}$ Coupling of ${ }^{1} \mathrm{H}$-NMR metabolic analyses to biochemical experiments revealed that HIPK2 depletion led to increased lactate production and glycolytic metabolism that likely contributed to adaptation to hypoglycemic environment.
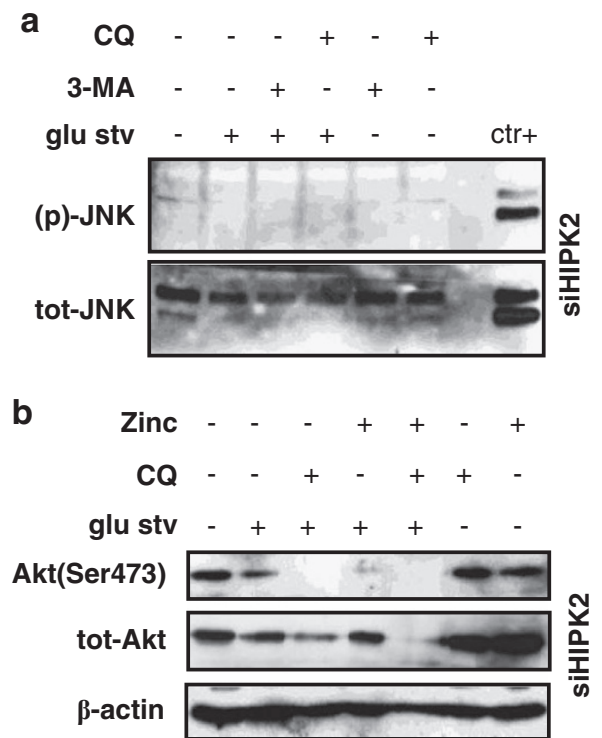

Figure 7 Akt phosphorylation is inhibited by $C Q$ and zinc treatments. (a) Equal amount of total cell extracts from siHIPK2 cells left untreated or treated for $24 \mathrm{~h}$ with glucose-free medium (glu stv) alone or in combination with autophagy inhibitors 3MA $(5 \mathrm{mM})$ or $\mathrm{CQ}(25 \mu \mathrm{M})$ were assayed by western immunoblotting of JNK phosphorylation and total JNK levels. A sample of HIPK2 ${ }^{+/+}$cells treated with glucose restriction for $24 \mathrm{~h}$ is included as positive control $(\mathrm{ctr}+)$. (b) Equal amount of total cell extracts from siHIPK2 cells left untreated or treated for $24 \mathrm{~h}$ with glucosefree medium (glu stv) alone or in combination with CQ $(25 \mu \mathrm{M})$ or ZnCl2 $(100 \mu \mathrm{M})$ were assayed by western immunoblotting of Akt phosphorylation and total Akt levels. $\beta$-actin is used as protein loading control. A representative result out of two independent experiments is shown

HIPK2 is an oncosuppressor and a corepressor molecule that can stimulate gene expression upon phosphorylation of several transcription factors including $p 53,6,16,17$ and repress transcription of several genes involved in development, apoptosis, and tumor progression such as HIF-1 $\alpha^{7} \mathrm{HIF}-1$ enhances glycolysis by inducing the expression of genes encoding glycolytic enzymes and glucose transporters, such as Glut-1, ${ }^{5}$ which was indeed increased in siHIPK2 cells. Similarly, p53 has important roles in the regulation of glycolysis and oxidative phosphorylation in cancer cells. ${ }^{23-25}$ Loss of p53 enhances aerobic glycolysis, resulting in the development of a more aggressive tumor. ${ }^{24}$ Given the multiplicity of molecules modulated by HIPK2, one cannot assume that only one pathway might be involved. One of the mechanism involved in late $(24 \mathrm{~h})$ apoptosis/necrosis upon glu stv was p53Ser46 phosphorylation that was abolished in siHIPK2 cells. At earlier time point (16 h), JNK was activated in HIPK2 ${ }^{+/+}$cells upon glucose restriction and its activity was markedly impaired by HIPK2 depletion. JNK1 has important roles in triggering apoptosis in response to cellular stress, and its activation by HIPK2 has been previously reported. ${ }^{19}$ However, the role of HIPK2 activation in JNK activation upon glucose restriction needs to be further elucidated because several signaling kinases may regulate survival during glu stv. ${ }^{30}$ To render cancer cells sensitive to glucose depletion may potentially provide an effective strategy for cancer intervention. However, Glut-1 silencing or targeting glucose metabolism with 2-DG did not induce siHIPK2 cell death in this 
setting, suggesting the activation of additional pathways. Zinc supplementation inhibited siHIPK2 lactate production that correlated with increased cell death, likely by reversing p53 misfolding ${ }^{20,21,23,25}$ and by inhibiting HIF-1 activity. $^{13}$

Cancer cells encountering limited nutrient supplies in the growing tumor may exploit autophagy for survival; thus, autophagy contributes to the tolerance to nutrient deprivation in colorectal cancer cells. ${ }^{39}$ In agreement, autophagy was induced upon glu stv in both HIPK2 ${ }^{+/+}$and siHIPK2 cells, and blocking autophagy increased glucose-starving HIPK2 ${ }^{+/+}$ cell death and re-established siHIPK2 cell death. What was the mechanism that re-established glucose-starving siHIPK2 cell death upon autophagy inhibition? Autophagy inhibition markedly impaired Akt phosphorylation in glucose-starving siHIPK2 cells, which could partly support re-establishment of siHIPK2 cell sensitivity to metabolic stress-induced cell death. The inhibition of autophagy has been shown to enhance the therapeutic benefits of various cancer therapies; however, strategies to induce autophagic cell death (that is, metformin) have also been proposed to inhibit tumor progression; ${ }^{47,48}$ therefore, modulation of autophagy for cancer therapy is still somehow controversial. ${ }^{26}$

In cancer, the importance of HIPK2 has been elucidated by HIPK2 knock-out mice that showed increased sensitivity to develop skin cancer after treatment with carcinogens. ${ }^{49}$ Moreover, loss of HIPK2 heterozigosity occurs in radiationinduced tumors in mouse cells $s^{50}$ and in human papillary thyroid cancers, ${ }^{51}$ underlining the important activity of HIPK2 as tumor suppressor. HIPK2 may be inhibited in tumors by several mechanisms such as hypoxia-induced protein degradation, gene mutation, or oncogene-mediated cytoplasmic localization. ${ }^{9}$ Although glucose deprivation has been shown to activate metabolic and signaling pathways inducing cell death, ${ }^{52}$ molecular alterations leading to HIPK2 impairment could counteract this effect increasing tumor resistance to metabolic stress. Glucose restriction can be obtained by reduced angiogenesis or by low carbohydrate diet that indeed has been shown to slow tumor growth. ${ }^{53}$ On the contrary, higher dietary glycemic load associates with an increased risk of recurrence and mortality in stage III colon cancer patients. ${ }^{54}$ Thus, we found here that both cell lines were still capable of resuming cell proliferation as soon as nutrient supply was provided, in line with the concept that tumor cells develop tolerance to nutrient deprivation that can therefore contribute to tumor progression. ${ }^{2}$ More recently, glucose restriction has been shown to reduce mutant p53 pro-oncogenic function, ${ }^{55}$ whereas supplemental zinc reactivates mutant $p 53 .{ }^{56}$ Therefore, dietetic intervention aimed at lowering the glucose intake along with supplemental zinc could be an efficient strategy to increase cell death in tumors with HIPK2 or p53 impairment. In addition, HIPK2 transduction might be a useful prospective as potential targeted cancer gene therapy approach to circumvent resistance to cell death. ${ }^{57,58}$

\section{Materials and Methods}

Cell culture and treatments. Human RKO colon cancer (carrying wtp53; HIPK2 ${ }^{+1+}$ ), the RKO stably interfered for HIPK2 (siHIPK2), ${ }^{27}$ and the human lung cancer H1299 (p53 null) cells were routinely maintained in DMEM (Life Technology-Invitrogen) medium containing 10\% heat-inactivated fetal bovine serum (Life Technology-Invitrogen, Carlsbad, CA, USA), 100 units/ml penicillin/ streptomycin, and glutamine, in $5 \% \mathrm{CO}_{2}$ humidified incubator at $37^{\circ} \mathrm{C}$. For glu stv, cells were transferred to corresponding medium without glucose. Glucose-free DMEM was supplemented with full medium to achieve the desired concentration of glucose (full DMEM contains $25 \mathrm{mM}$ glucose and was diluted in glucose-free DMEM 10-fold to achieve concentration of $2.5 \mathrm{mM}$ ).

Chemicals. $\mathrm{ZnCl}_{2}$ was dissolved in $\mathrm{dH}_{2} \mathrm{O}_{2}$ and used at $100 \mu \mathrm{M}$; 3-MA was dissolved in $\mathrm{dH}_{2} \mathrm{O}_{2}$ and used at $5 \mathrm{mM} ; 2-\mathrm{DG}$ was dissolved in DMSO and used at concentrations ranging between 4 and $12 \mathrm{mM} ; \mathrm{CQ}$ was dissolved in $\mathrm{dH}_{2} \mathrm{O}_{2}$ and used at $25 \mu \mathrm{M}$. All chemicals were from Sigma-Aldrich (St. Louis, MO, USA). $\mathrm{ZnCl}_{2}$, 3-MA, and $\mathrm{CQ}$ were added to culture media1 $\mathrm{h}$ before treatments.

Measurement of cell proliferation and viability. Cells numbers were determined in duplicate at different time points. Cell counts were performed using a hemocytometer by adding trypan blue to equal volume of cell suspension. The percentage of cell viability, as blue/total cells, was assayed by scoring 200 cells per well three times. Bright field images were taken in a Nikon Eclipse TS100 microscope equipped with a Nikon ELWD camera (Nikon Instruments Europe BV, Amsterdam, Netherlands). For survival assay, $2 \times 10^{5}$ cells were plated on $60-\mathrm{mm}$ dishes and $24 \mathrm{~h}$ later treated with glucose-free medium. Death-resistant cells were stained with crystal violet $24-48 \mathrm{~h}$ later.

Annexin V/PI staining. Apoptosis was quantified by cytofluorimetric analysis staining cells simultaneously with FITC-Annexin $\mathrm{V}$ and the non-vital dye PI (Immunological Sciences, Rome, Italy), following the manufacturer's instruction. At the end of incubation with the respective reagents, samples were analyzed with a FACScan instrument (Becton Dickinson Europe Holdings SAS - Le Pont De Claix, France). About 30000 events were acquired and gated using forward scatter and side scatter to exclude cell debris. Bivariate analysis allows the discrimination of intact cells ( $\mathrm{FITC}^{-} \mathrm{PI}^{-}$), early apoptotic ( $\mathrm{FITC}^{+} \mathrm{PI}^{-}$), and late apoptotic or necrotic cells $\left(\mathrm{FITC}^{+} \mathrm{PI}^{+}\right)$. The percentage of Annexin $\mathrm{V}^{+}$cells relatives to the different analyses was calculated using CellQuest software (Becton Dickinson). FITCconjugated Annexin V/PI staining (Immunological Sciences) was also visualized by Olympus BX53 fluorescence microscope (Olympus Italia Srl, Milan, Italy).

Measurement of lactate. Cells were seeded onto $35-\mathrm{mm}$ tissue-culture dishes, and $24 \mathrm{~h}$ later washed three times in PBS before adding glucose-free media for $16 \mathrm{~h}$. Lactate secretion of triplicates were measured by using the Lactate Assay Kit II (BioVision Research Products, Mountain View, CA, USA), according to the manufacturer's instruction.

RNA isolation and RT-PCR analysis. Cells were harvested in TRIzol Reagent (Invitrogen, Carlsbad, CA, USA) and total RNA was isolated following the manufacturer's instructions. CDNA was synthesized from $2 \mu \mathrm{g}$ of total RNA with MuLV reverse transcriptase kit (Applied Biosystems, Life-Technology-Invitrogen). Semiquantitative reverse transcription (RT)-PCR was carried out by using HotMaster Taq polymerase (Eppendorf Srl, Milano, Italy) with $2 \mu \mathrm{l}$ cDNA reaction and genes-specific oligonucleotides under conditions of linear amplification. The housekeeping $\beta$-actin was used as internal standard.

Western blotting. Total cell extracts were prepared by incubation in lysis buffer $(50 \mathrm{mM}$ Tris- $\mathrm{HCl}$, pH 7.5, $150 \mathrm{mM} \mathrm{NaCl}, 5 \mathrm{mM}$ EDTA, pH 8.0, $150 \mathrm{mM} \mathrm{KCl}$, $1 \mathrm{mM}$ dithiothreitol, $1 \%$ Nonidet P-40) and a mix of protease and phosphatase inhibitors (Sigma-Aldrich Chemical Company, Sigma-Aldrich). Samples were denatured in SDS sample buffer. Total proteins were separated by loading 20 $60 \mu \mathrm{g}$ of total cell lysates on denaturing $10 \%$ SDS-PAGE and transferred to a polyvinylidene difluoride membrane (Merck Millipore, Billerica, MA, USA). Membranes were blocked with $5 \%$ nonfat dry milk in PBS and incubated with primary antibodies that recognize: cyclin B1, Glut-1 (H-43), p53 (DO-1; all from Santa Cruz Biotechnology, Santa Cruz, CA, USA), PARP (cleavage site-214/215, Millipore), LC3B (Sigma-Aldrich), HA (Roche S.p.A, Milan, Italy), (p)JNK, JNK, (p)c-Jun, c-Jun, (p)Ser46, (p)-Akt (Ser473), tot-Akt, (all from Cell Signaling Technologies, Danvers, MA, USA), HIPK2 (kindly provided by ML Schmitz, JustusLiebig University, Giessen, Germany), $\beta$-actin (Calbiochem, San Diego, CA, USA), and tubulin (Immunological Sciences). Secondary antibody conjugated to horseradish peroxidise (Bio-Rad Laboratories, Hercules, CA, USA) was used to detect primary antibodies, and enzymatic signals were visualized by chemoluminescence (ECL kit, Amersham Biosciences, Freiburg, Germany). 
Transfection and plasmids. Cells were transfected by using the LipofectaminePlus method (Invitrogen), according to the manufacturer's specifications. The amount of plasmid DNA was equalized in each sample by supplementing with empty vector, and transfection efficiency was visualized with the use of a co-transfected GFP expression vector. For stable transfection, $4 \times 10^{5}$ RKO cells were transfected with the nonphosphorylatable (competitive inhibitor) HA-JNK1-APF (dominant negative, DN-JNK1)31 (kindly provided by Lynn E Heasley, University of Colorado, Aurora, CO). Forty-eight hours after transfection, cells underwent selection with geneticin G418 (1 mg/ml). G418resistant cells were pooled as mixed population 2 weeks later.

siRNA interference. Cells were plated at semiconfluence in 35-mm dishes the day before transfection. Control-siRNA and siGlut-1 (Dharmacon, ThermoScientific, Fisher Scientific SAS, Illkirch Cedex, France) were transfected overnight using LipofectaminePlus reagent (Invitrogen).

ChIP assay. H1299 cells were plated at subconfluence in 150-mm petridishes. The day after plating, cells were washed in PBS three times and glucose-free medium was added for $8 \mathrm{~h}$. Protein complexes were cross-linked to DNA in living cells by adding formaldehyde directly to the cell vulture medium at $1 \%$ final concentration, essentially as described. ${ }^{7}$ Chromatin extracts containing DNA fragments with an average size of $500 \mathrm{bp}$ were incubated overnight at $4{ }^{\circ} \mathrm{C}$ with milk shaking using rabbit polyclonal anti-HIPK2 (H-55, Santa Cruz Biotechnology) antibody. Before use, protein G (Pierce, Thermo-Scientific, Fisher Scientific SAS) was blocked with $1 \mu \mathrm{g} / \mu \mathrm{l}$ sheared herring sperm DNA and $1 \mu \mathrm{g} / \mu \mathrm{l}$ BSA for $3 \mathrm{~h}$ at $4^{\circ} \mathrm{C}$, and then incubated with chromatin and antibodies for $2 \mathrm{~h}$ at $4{ }^{\circ} \mathrm{C}$. PCR was performed with HOT-MASTER Taq (Eppendorf) using $2 \mu$ l of immuniprecipitated DNA and promoter-specific primers for human HIF-1 $\alpha$ promoter. Immunoprecipitation with nonspecific immunoglobulins (IgG; Santa Cruz Biotechnology) was performed as negative controls. The amount of precipitated chromatin measured in each PCR was normalized with the amount of chromatin present in the input of each immunoprecipitation. PCR products were run on a $2 \%$ agarose gel and visualized by ethidium bromide staining using UV light.

Cell extracts in aqueous phase. Cells grown to $60-70 \%$ confluence were trypsinized $24 \mathrm{~h}$ after culture medium change, counted, and assessed for viability $(80-90 \%)$ and membrane integrity by trypan blue staining. Cells $\left(3 \times 10^{6}\right.$ cells per sample) were washed twice with ice-cold physiological saline solution, resuspended in $0.5 \mathrm{ml}$ ice-cold twice-distilled water, and aqueous extracts were prepared in $\mathrm{EtOH}: \mathrm{H}_{2} \mathrm{O}\left(70: 30\right.$, v/v), as previously described. ${ }^{56}$ Samples were ultrasonicated at $20 \mathrm{kHz}$ with an exponential probe, $8 \mu \mathrm{m}$ peak-to-peak by a MSE ultrasonic disintegrator Mk2 (Crawley, Sussex, UK) and centrifuged at $14000 \times \mathrm{g}$ for $30 \mathrm{~min}$. Supernatants were lyophilized twice in a RVT 4104 Savant lyophilizer (Mildford, Main, MA, USA), and the residue diluted in $0.7 \mathrm{ml}$ deuterium oxide (Sigma-Aldrich, Milan, Italy) containing $0.1 \mathrm{mM} \mathrm{3-(trimethylsilyl)-propionic-2,2,3,3-d4} \mathrm{acid} \mathrm{sodium}$ salt (TSP) as internal standard (Merck \& Co., Montreal, QC, Canada).

High-resolution NMR spectroscopy. High-resolution NMR experiments $\left(25^{\circ} \mathrm{C}\right.$ ) were performed at $400 \mathrm{MHz}$ (Bruker AVANCE spectrometer, Bruker $\mathrm{GmbH}$, Karlsruhe, Germany). ${ }^{1} \mathrm{H}-\mathrm{MRS}$ spectra of cell extracts were obtained using acquisition pulses, water presaturation, data processing, and data analysis, as previously described. ${ }^{59}$ Quantification of individual metabolites was obtained from peak areas using correction factors determined by experiments at the equilibrium of magnetization ( $90^{\circ}$ pulses, $30.00 \mathrm{~s}$ interpulse delay). Metabolite quantification was expressed as nanomoles and normalized to the number of extracted cells.

Statistical analysis. PCA were performed on AMIX software (Bruker $\mathrm{GmbH})$. The spectral region between 4.7 and 0.5 p.p.m. of each NMR spectrum was binned in 21 variable size buckets corresponding to known metabolites. The rows (samples) of the data matrix were scaled to reference regions (TSP, $0.1 \mathrm{mM}$ in $700 \mu \mathrm{l}$ sample). The columns (variables) were not scaled. Confidence level (T2 Hotelling ellipses were calculated to $80 \%$ ). Data were analyzed using Excel software. Statistical significance of differences was determined by Student $t$-test (as specified). Differences were considered significant at $P<0.05$.

All experiment unless indicated were performed at least three times. All experimental results were expressed as the arithmetic mean, and S.D. of measurements was shown. Student's $t$-test was used for statistical significance of the differences between treatment groups. Statistical analysis was performed using analysis of variance at $5 \%(P<0.05)$ or $1 \%(P<0.01)$.

\section{Conflict of Interest}

The authors declare no conflict of interest.

Acknowledgements. This study was supported by grant form Associazione Italiana per la Ricerca sul Cancro (AIRC, IG 11377, to GD) and My First AIRC grant (MFAG 11502, to DT). We are greatly indebted to Drs. L Di Renzo and G Bossi for their helpful advice, stimulating discussion and for sharing reagents. GD dedicates this study to the memory of Professor David Givol who with a combination of intelligence, passion, vision, and organization was a precious and challenging collaborator and an unforgettable friend. We also dedicate this study to the memory of Professor Rita Levi Montalcini. May her outstanding contribution to science be an immortal legacy and an example for us all.

\section{Author contributions}

GD designed the research; AG, AR, DT, EDI, GP, GD performed the research; GD, $A R, D T, E D I, G C, M C$ analyzed the data; and GD wrote the paper.

1. Folkman J. Can mosaic tumor vessels facilitate molecular diagnosis of cancer? Proc Natl Acad Sci USA 2001; 98: 398-400.

2. Izuishi K, Kato K, Ogura T, Kinoshita T, Esumi H. Remarkable tolerance of tumor cells to nutrient deprivation: possible new biochemical target for cancer therapy. Cancer Res 2000; 60: 6201-6207.

3. Esumi H, Izuishi K, Kato K, Hashimoto K, Kurashima Y, Kishimoto A et al. Hypoxia and nitric oxide treatment confer tolerance to glucose starvation in a $5^{\prime}$-AMP-activated protein kinase-dependent manner. J Biol Chem 2002; 277: 32791-32798.

4. Hanahan D, Weinberg RA. Hallmarks of cancer: the next generation. Cell 2011; 144 646-674.

5. Semenza GL. Defining the role of hypoxia-inducible factor 1 in cancer biology and therapeutics. Oncogene 2010; 29: 625-634.

6. Rinaldo C, Prodosmo A, Siepi F, Soddu S. HIPK2: a multitalented partner for transcription factors in DNA damage response and development. Biochem Cell Biol 2007; 85: 411-418.

7. Nardinocchi L, Puca R, Guidolin D, Belloni AS, Bossi G, Michiels C et al. Transcriptional regulation of hypoxia-inducible factor 1 alpha by HIPK2 suggests a novel mechanism to restrain tumor growth. Biochim Biophys Acta MCR 2009; 1793: 368-377.

8. D'Orazi G, Sciulli MG, Di Stefano V, Riccioni S, Frattini M, Falcioni R et al. Homeodomaininteracting protein kinase-2 restrain cytosolic phospholipase A2-dependent prostaglandin E2 generation in human colorectal cancer cells. Clin Cancer Res 2006; 12: 735-741.

9. D'Orazi G, Rinaldo C, Soddu S. Updates on HIPK2: a resourceful oncosuppressor for clearing cancer. J Exp Clin Cancer Res 2012; 31: 63.

10. Calzado MA, de la Vega L, Moller A, Bowtell DD, Schmitz ML. An inducible autoregulatory loop between HIPK2 and Siah2 at the apex of the hypoxic response. Nat Cell Biol 2009; 11: 85-91.

11. Nardinocchi L, Puca R, D'Orazi G. HIF-1 $\alpha$ antagonizes p53-mediated apoptosis by triggering HIPK2 degradation. Aging (Albany NY) 2011; 3: 33-43.

12. Nardinocchi L, Puca R, Sacchi A, Rechavi G, Givol D, D'Orazi G. Targeting hypoxia in cancer cells by restoring homeodomain-interacting protein kinase-2 and p53 activity and suppressing HIF-1alpha. PloS ONE 2009; 4: e6819.

13. Nardinocchi L, Pantisano V, Puca R, Porru M, Aiello A, Grasselli A et al. Zinc downregulates HIF-1 $\alpha$ and inhibits its activity in tumor cells in vitro and in vivo. PLOS ONE 2010; 5: e15048.

14. Sheffer M, Simon AJ, Rechavi G, Domany E, Givol D, D'Orazi G. Genome-wide analysis discloses reversal of the hypoxia-induced changes of gene expression in colon cancer cells by zinc supplementation. Oncotarget 2011; 2: 1191-1202.

15. Puca R, Nardinocchi L, Givol D, D'Orazi G. Regulation of p53 by HIPK2: molecular mechanisms and therapeutical implications in human cancer cells. Oncogene 2010; 29: 4378-4387.

16. D'Orazi G, Cecchinelli B, Bruno T, Manni I, Higashimoto Y, Saito S et al. Homeodomaininteracting protein kinase-2 phosphorylates p53 at Ser46 and mediates apoptosis. Nature Cell Biol 2002; 4: 11-19.

17. Hofmann TG, Moller A, Sirma H, Zentgraf H, Taya Y, Droge W et al. Regulation of p53 activity by its interaction with homeodomain-interacting protein kinase-2. Nature Cell Biol 2002; 4: 1-10.

18. Puca R, Nardinocchi L, Sacchi A, Rechavi G, Givol D, D'Orazi G. HIPK2 modulates p53 activity towards pro-apoptotic transcription. Mol Cancer 2009; 14: 85.

19. Hofmann TG, Stollberg N, Schmitz ML, Will H. HIPK2 regulates transforming growth factor$\beta$-induced c-Jun $\mathrm{NH} 2$-terminal kinase activation and apoptosis in human hepatoma cells. Cancer Res 2003; 63: 8271-8277.

20. Puca R, Nardinocchi L, Gal H, Rechavi G, Amariglio N, Domany E et al. Reversible dysfunction of wild-type p53 following homeodomain-interacting protein kinase-2 knockdown. Cancer Res 2008; 68: 3707-3714.

21. Puca R, Nardinocchi L, Bossi G, Sacchi A, Rechavi G, Givol D et al. Restoring wtp53 activity in HIPK2 depleted MCF7 cells by modulating metallothionein and zinc. Exp Cell Res 2009; 315: 67-75. 
22. Loh SN. The missing Zinc: p53 misfolding and cancer. Metallomics 2010; 2: 442-449.

23. Vousden KH, Ryan KM. P53 and metabolism. Nat Rev Cancer 2009; 9: 691-700.

24. Salminen A, Kaarniranta K. Glycolysis links p53 function with NF-kappa B: impact on cancer and aging process. J Cell Physiol 2010; 22: 1-6.

25. Jiang $P$, Du W, Wang X, Mancuso A, Gao X, Wu M et al. p53 regulates biosynthesis through direct inactivation of glucose-6-phosphate dehydrogenase. Nat Cell Biol 2011; 13 310-316.

26. Choi KS. Autophagy and cancer. Exp Mol Med. 2012; 44: 109-120.

27. Di Stefano V, Rinaldo C, Sacchi A, Soddu S, D'Orazi G. Homeodomain-interacting protein kinase-2 activity and p53 phosphorylation are critical events for cisplatin-mediated apoptosis. Exp Cell Res 2004; 293: 311-320.

28. Lindon JC, Nicholson JK. Spectroscopic and statistical techniques for information recovery in metabonomics and metabolomics. Annu Rev Anal Chem (Palo Alto Calif) 2008; 1 45-69.

29. Podo F, Canevari S, Canese R, Pisanu ME, Ricci A, lorio E. MR evaluation of response to targeted treatment in cancer cells. NMR Biomed 2011; 24: 648-672.

30. Munoz-Pinedo C, Miliyad NE, Ricci J-E. Cancer metabolism: current perspectives and future directions. Cell Death Dis 2012; 3: 1-10.

31. Okoshi R, Ozaki T, Yamamoto H, Ando K, Koida N, Ono S et al. Activation of AMPactivated protein kinase induces p53-dependent apoptotic cell death in response to energetic stress. J Biol Chem 2008; 283: 3979-3987.

32. Butterfield L, Storey B, Maas L, Heasley LE. C-Jun NH2-terminal kinase regulation of the apoptotic response of small cell lung cancer cells to ultraviolet radiation. J Biol Chem 1997; 272: 10110-10116.

33. Gresko E, Roscic A, Ritterhoff S, Vichalkovski A, Del Sal G, Schmitz ML. Autoregulatory control of the p53 response by caspase-mediated processing of HIPK2. EMBO J 2006; 25: 1883-1894.

34. Maschek G, Savaraj N, Priebe W, Braunschweiger P, Hamilton K, Tidmarsh GF et al. 2-deoxy-D-glucose increases the efficacy of adryamicin and paclitaxel in human osteosarcoma and non-small cell lung cancers in vivo. Cancer Res 2004; 64: 31-34.

35. Sahra IB, Laurent K, Giuliano S, Larbret F, Ponzio G, Gounon P et al. Targeting cancer cell metabolism. The combination of metformin and 2-deoxyglucose induces p53-dependent apoptosis in prostate cancer cells. Cancer Res 2010; 70: 2465-2475.

36. Sciortino S, Gurtner A, Manni I, Fontemaggi G, Dey A, Sacchi A et al. The cyclin B1 gene is actively transcribed during mitosis in HeLa cells. EMBO Rep 2001; 11: 1018-1023.

37. Locasale JW, Cantley LC, Vander Heiden MG. Cancer's insatiable appetite. Nat Biotechnol 2009; 10: 916-917.

38. Schwartzenberg-Bar-Yoseph F, Armoni M, Karnieli E. The tumor suppressor p53 downregulates glucose transporters GLUT1 and GLUT4 gene expression. Cancer Res 2004; 64 : 2627-2633.

39. Sato K, Tsuchihara K, Fujii S, Sugiyama M, Goya T, Atomi Y et al. Autophagy is activated in colorectal cancer cells and contributes to the tolerance to nutrient deprivation. Cancer Res 2007; 67: 9677-9684.

40. Barth S, Glick D, Macleod KF. Autophagy: assays and artifacts. J Pathol2010; 221: 117-124.

41. Terman A, Gustafsson B, Brunk UT. The lysosomal-mitochondrial axis theory of postmitotic aging and cell death. Chem Biol Interact 2006; 163: 29-37.

42. Michihara A, Toda K, Kubo T, Fujiwara Y, Akasaki K, Tsuji H. Disruptive effect of choroquine on lysosomes in cultured rat hepatocytes. Biol Pharm Bull 2005; 28: 947-951.

43. Bon G, Di Carlo S, Folgiero V, Avetrani P, Lazzari C, D'Orazi G et al. Negative regulation of b4 integrin transcription by homeodomain-interacting protein kinase 2 and p53 impairs tumor progression. Cancer Res 2009; 69: 5978-5986.
44. Vivanco I, Sawyers CL. The phosphatidylinositol 3-kinase-Akt pathway in human cancer. Nature Rev Cancer 2002; 2: 489-501.

45. Levine AJ, Puzio-Kuter AM. The control of the metabolic switch in cancers by oncogenes and tumor suppressor genes. Science 2010; 330: 1340-1348.

46. Cairns RA, Harris IS, Mak TW. Regulation of cancer cell metabolism. Nat Rev Cancer 2011; 11: 85-95.

47. Vara D, Salazar M, Olea-Herrero N, Guzmán M, Velasco G, Díaz-Laviada I. Anti-tumoral action of cannabinoids on hepatocellular carcinoma: role of AMPK-dependent activation of autophagy. Cell Death Diff 2011; 18: 1099-1111.

48. Tomic T, Botton T, Cerezo M, Robert G, Luciano F, Puissant A et al. Metformin inhibits melanoma development throughautophagy and apoptosis mechanisms. Cell Death Dis 2011; 2: e199.

49. Wei G, Ku S, Ma GK, Saito S, Tang AA, Zhang J et al. HIPK2 represses $\beta$-cateninmediated transcription, epidermal stem cell expansion, and skin tumorigenesis. Proc Nat Acad Sci USA 2007; 104: 13040-13045.

50. Mao JH, Wu D, Kim IJ, Kang HC, Wei G, Climent J et al. Hipk2 cooperates with p53 to suppress $\gamma$-ray radiation-induced mouse thymic lymphoma. Oncogene 2011; 31: $1176-1180$.

51. Lavra L, Rinaldo C, Ulivieri A, Luciani E, Fidanza P, Giacomelli L et al. The loss of the p53 activator HIPK2 is responsible for Galectin-3 overexpression in well differentiated thyroid carcinomas. PLOS ONE 2011; 6: e20665.

52. Graham NA, Tahmasian M, Kohli B, Komisipoulou E, Zhu M, Vivanco I et al. Glucose deprivation activates a metabolic and signaling loop leading to cell death. Mol Syst Biol 2012; 8: 589.

53. Ho VW, Leung K, Hsu A, Luk B, Lai J, Shen SY et al. A low carbohydrate, high protein diet slows tumor growth and prevents cancer initiation. Cancer Res 2011; 71: 4484-4493.

54. Meyerhardt JA, Sato K, Niedzwiecki D, Ye C, Saltz LB, Mayer RJ et al. Dietary glycemic load and cancer recurrence and survival in patients with stage III colon cancer: findings from CALGB 89803. J Natl Cancer Inst 2012; 104: 1702-1711.

55. Rodriguez OC, Choudhury S, Kolukula V, Vietsch EE, Catania J, Preet A et al. Dietary downregulation of mutant p53 levels via glucose restriction. Cell Cycle 2012; 11: 4436-4446.

56. Puca R, Nardinocchi L, Porru M, Simon AJ, Rechavi G, Leonetti C et al. Restoring p53 active conformation by zinc increases the response of mutant $\mathrm{p} 53$ tumor cells to anticancer drugs. Cell Cycle 2011; 10: 1679-1689.

57. Puca R, Nardinocchi L, Pistritto G, D'Orazi G. Overexpression of HIPK2 circumvents the blockade of apoptosis in chemoresistant cancer cells. Gynecol Oncol 2008; 109: 403-410.

58. Nardinocchi L, Puca R, Sacchi A, D'Orazi G. Inhiition of HIF-1-alpha activity by homeodomain-interacting protein kinase-2 correlates with sensitization of chemoresistant cells to undergo apoptosis. Mol Cancer 2009; 8: 1

59. Iorio $\mathrm{E}$, Ricci A, Bagnoli M, Pisanu ME, Castellano G, Di Vito M et al. Activation of phosphatidylcholine cycle enzymes in human epithelial ovarian cancer cells. Cancer Res 2010; 70: 2126-2135

(c) ()ㅇ Cell Death and Disease is an open-access journal cc) published by Nature Publishing Group. This work is licensed under a Creative Commons Attribution-NonCommercialNoDerivs 3.0 Unported License. To view a copy of this license, visit http://creativecommons.org/licenses/by-nc-nd/3.0/ 